\title{
What is the best way to represent surface conductance for a range of vegetated sites?
}

\author{
Hikaru Komatsu, ${ }^{1,2 *}$ Norifumi Hotta ${ }^{3}$ and Tomonori Kume ${ }^{3}$ \\ ${ }^{1} \mathrm{Oki} /$ Kanae Lab., Institute of Industrial Science, The University of Tokyo, Japan \\ ${ }^{2}$ Research Fellow of the Japan Society for the Promotion of Science, Japan \\ ${ }^{3}$ Graduate School of Agricultural and Life Sciences, The University of Tokyo, Japan
}

\begin{abstract}
:
Surface conductance $G_{s}$ is a significant parameter for indicating the evaporative and photosynthetic properties of a vegetated surface. When comparing $G_{s}$ values between different observation sites, some studies have used $G_{s m a x}$ and others have used $\hat{G}_{\text {smax }}$ (where $G_{\text {smax }}$ is the maximum $G_{s}$ value measured during the measurement period, and $\hat{G}_{\text {smax }}$ is the maximum $G_{s}$ value obtained with a vapour pressure deficit (VPD) of $\geq 1.0 \mathrm{kPa}$ during the measurement period).

In this study, we demonstrate a clear justification for using $\hat{G}_{s m a x}$ instead of $G_{\text {smax }}$ when comparing $G_{s}$ values between different sites. We examined whether both $\hat{G}_{\text {smax }}$ and $G_{\text {smax }}$ lead to the same conclusions in classifying vegetated sites. Komatsu (2003b) [Hydrological Processes 17: 2503-2512] reported a clear relationship between canopy height $h$ and $\hat{G}_{\text {smax }}$ for coniferous forests with a projected leaf area index (LAI) of $\geq 3 \cdot 0$. We examined not only the relationship between $h$ and $\hat{G}_{\text {smax }}$ but also the relationship between $h$ and $G_{\text {smax }}$ for coniferous forests with a projected LAI of $\geq 3 \cdot 0$.

Both $\hat{G}_{\text {smax }}$ and $G_{\text {smax }}$ decreased with increasing $h$. However, the relationship between $h$ and $G_{\text {smax }}$ was less well defined than the relationship between $h$ and $\hat{G}_{\text {smax }}$ because of biased $G_{\text {smax }}$ data. Consequently, we conclude that $\hat{G}_{\text {smax }}$ is a more appropriate index than $G_{\text {smax }}$ to represent $G_{s}$ for sites with different vegetation. Copyright (c) 2007 John Wiley \& Sons, Ltd.
\end{abstract}

KEY WORDS surface conductance; maximum surface conductance; vegetation; vapour pressure deficit

Received 14 April 2005; Accepted 4 August 2005

\section{INTRODUCTION}

Surface conductance $G_{s}$ is an important parameter used to indicate the evaporative and photosynthetic properties of a vegetated surface. $G_{s}$ is calculated from the evapo-transpiration rate using the inverse form of the Penman-Monteith equation (Dolman et al., 1991; Kelliher et al., 1997, 1998; Kumagai et al., 2004; Komatsu et al., 2005); it indicates the significance of physiological control of evaporation by plants (Kelliher et al., 1995; Raupach, 1995; Baldocchi and Meyers, 1998; Lai et al., 2000). Since the stomata control photosynthesis as well as evapo-transpiration (Leuning, 1990, 1995; Jones, 1992; Campbell and Norman, 1998; Komatsu et al., 2007), $G_{s}$ also indicates the significance of physiological photosynthesis control (e.g. Schulze et al., 1994, 1995).

We can use $G_{s}$ to quantify differences in the significance of physiological control between observation sites (Shuttleworth, 1989; Kelliher et al., 1993, 1995; Schulze et al., 1994, 1995; Dolman et al., 1998; Kostner, 2001; Komatsu, 2003a,b, 2005; Komatsu and Hotta, 2005). In this way, we can quantify differences in the evaporative and photosynthetic properties not only of observation sites but also of different vegetation categories.

\footnotetext{
* Correspondence to: Hikaru Komatsu, Kasuya Research Forest, Kyushu University, 394 Tsubakuro, Sasaguri, Kasuya, Fukuoka 811-2415, Japan. E-mail: komatsu@forest.kyushu-u.ac.jp
}

Such comparisons are improved by using an index based on $G_{s}$, but with reduced dependence on varying meteorological conditions (Tan and Black, 1976; Stewart, 1988; Komatsu, 2004; Kumagai et al., 2004). To compare $G_{s}$ values from different observation sites, we thus need to determine a reference $G_{s}$ value that is not affected by meteorological differences between sites.

Many studies have represented $G_{s}$ by $G_{\text {smax }}$, where $G_{\text {smax }}$ is the maximum $G_{s}$ value obtained during the measurement period (Kelliher et al., 1993, 1995; Schulze et al., 1994, 1995; Dolman et al., 1998; Kostner, 2001). As $G_{s}$ decreases with increasing vapour pressure deficit (VPD) (e.g. Herbst, 1995; Law et al., 2001; Humphreys et al., 2003; Blanken and Black, 2004), $G_{\text {smax }}$ is usually measured in low VPD conditions.

In contrast to these studies that use $G_{\text {smax }}$, Komatsu (2003a,b, 2005) represented $G_{s}$ by $\hat{G}_{\text {smax }}$, where $\hat{G}_{\text {smax }}$ is the maximum $G_{s}$ value obtained with VPD $\geq 1.0 \mathrm{kPa}$ during the measurement period. As $G_{s}$ decreases with increasing VPD (Herbst, 1995; Law et al., 2001; Humphreys et al., 2003; Blanken and Black, 2004), $\hat{G}_{\text {smax }}$ is usually found when VPD is just above $1.0 \mathrm{kPa}$. Thus, use of $\hat{G}_{\text {smax }}$ avoids selecting $G_{s}$ in low VPD conditions (VPD $<1.0 \mathrm{kPa}$ ) as the reference value for the site, but this use of $\hat{G}_{\text {smax }}$ is not yet commonly accepted. A similar concept has been employed in several studies (Komatsu, 2003a,b, 2005) for modelling surface or canopy conductance. Granier et al. (1996a,b, 
2000); Oren et al. (1999); Komatsu (2004); Ewers et al. (2005) and Komatsu et al. (2006) gave reference values at $\mathrm{VPD}=1.0 \mathrm{kPa}$ when modelling surface or canopy conductance. However, many well known studies have used reference values at VPD $=0.0 \mathrm{kPa}$ when modelling surface or canopy conductance (e.g. Lindroth, 1985; Gash et al., 1989; Granier and Loustau, 1994; OginkHendriks, 1995).

It would be useful to determine whether there is any advantage in using either $\hat{G}_{\text {smax }}$ or $G_{\text {smax }}$ to compare $G_{s}$ values between observation sites. Komatsu (2003a,b, 2005) speculated that using $\hat{G}_{\text {smax }}$ is better because $G_{s}$ data obtained in low VPD conditions can cause several problems, which are outlined in the next section. However, to our knowledge, no clear justification has been offered for preferring $\hat{G}_{\text {smax }}$ to $G_{\text {smax }}$.

We examined whether $\hat{G}_{\text {smax }}$ and $G_{\text {smax }}$ lead to the same results when comparing $G_{s}$ values between different observation sites. We show that the use of $\hat{G}_{\text {smax }}$ leads to clearer results than $G_{\text {smax }}$, and we conclude that $\hat{G}_{\text {smax }}$ is a more appropriate index than $G_{\text {smax }}$ when comparing $G_{s}$ values between different observation sites.

\section{THEORY}

This section describes the theoretical background for the use of $\hat{G}_{\text {smax }}$ instead of $G_{\text {smax }}$. Komatsu (2003a,b, 2005) speculated that $\hat{G}_{\text {smax }}$ is better in the following three respects.

First, $G_{\text {smax }}$ is highly dependent on the length of the measurement period (Kelliher et al., 1995; Dolman et al., 1998), while $\hat{G}_{\text {smax }}$ is not. $G_{\text {smax }}$ tends to be measured during high irradiance and low VPD conditions, which occur comparatively rarely. Therefore, $G_{\text {smax }}$ obtained from short-term measurements tends to be underestimated. On the other hand, $\hat{G}_{\text {smax }}$ tends to occur along with high irradiance and VPD just above $1.0 \mathrm{kPa}$ (Figure 1), a more common set of conditions. Therefore, $\hat{G}_{\text {smax }}$ obtained from short-term measurements does not tend to be underestimated as often as $G_{\text {smax }}$.

Second, $G_{\text {smax }}$ tends to be determined as a high $G_{s}$ value because of wet-canopy evaporation after rain or heavy dew, while $\hat{G}_{\text {smax }}$ does not. The $G_{s}$ of a wet canopy is generally higher than that of a dry canopy and tends to occur in low VPD conditions. Therefore, it is likely that a high $G_{s}$ value caused by wet-canopy evaporation will be selected as $G_{\text {smax }}$. This problem can usually be avoided by using $\hat{G}_{\text {smax }}$ instead of $G_{\text {smax }}$; (however, the problem may be avoided by careful data filtering when using $G_{\text {smax }}$ ).

Third, $G_{\text {smax }}$ tends to be strongly affected by error in VPD measurement, while $\hat{G}_{\text {smax }}$ does not. As $G_{\text {smax }}$ is usually obtained in low VPD conditions (Figure 1), a small absolute error in VPD measurement causes a large error in calculating $G_{s}$, as is the case when calculating stomatal conductance from sap-flux measurements (Ewers and Oren, 2000).

If there were no differences in the lengths of measurement periods, in the methods for eliminating $G_{s}$ data of

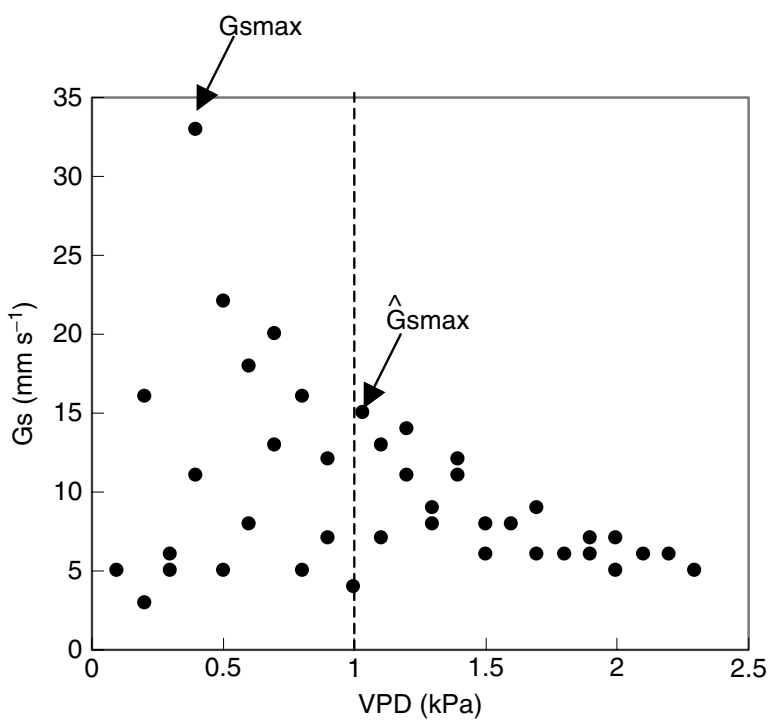

Figure 1. Schematic drawing of the relationship between VPD and surface conductance $G_{s}$. $\hat{G}_{\text {smax }}$ and $G_{\text {smax }}$ are illustrated, where $\hat{G}_{\text {smax }}$ is the maximum surface conductance satisfying VPD $\geq 1.0 \mathrm{kPa}$ during the measurement period, and $G_{s \max }$ is the maximum surface conductance during the measurement period

a wet canopy, and in the accuracy in VPD measurements between observation sites, $G_{\text {smax }}$ would correlate well with $\hat{G}_{\text {smax }}$, and both $\hat{G}_{\text {smax }}$ and $G_{\text {smax }}$ would produce nearly the same results when comparing $G_{s}$ values from different observation sites. In practice, however, there are differences in the lengths of measurement periods, in the methods for eliminating $G_{s}$ data of a wet canopy, and in the accuracy in VPD measurements between observation sites, and thus, there can be a bias in $G_{\text {smax }}$ estimates that does not apply to $\hat{G}_{\text {smax }}$. When using $G_{\text {smax }}$, such biased $G_{\text {smax }}$ samples can tend to confuse results more than when using $\hat{G}_{\text {smax }}$.

\section{MATERIALS AND METHODS}

We examined whether $\hat{G}_{\text {smax }}$ and $G_{\text {smax }}$ lead to the same results in the following way. We examined the relation between canopy height $h$ and $\hat{G}_{\text {smax }}$ and between $h$ and $G_{\text {smax }}$ for coniferous forests with a projected leaf area index (LAI) of $\geq 3 \cdot 0$. These relationships were then compared to each other. Komatsu (2003b) has shown that there is a clear relationship between $h$ and $\hat{G}_{\text {smax }}$ for coniferous forests. $\hat{G}_{\text {smax }}$ decreases with increasing $h$; this relation is especially strong when the projected LAI is $\geq 3.0\left(R^{2}=0.69\right)$. Our focus here was on whether $G_{\text {smax }}$ also decreased with increasing $h$, and whether the relationship between $h$ and $G_{\text {smax }}$ was as well defined as the relationship between $h$ and $\hat{G}_{\text {smax }}$.

For these comparisons, we used $G_{s}$ data derived from micrometeorological measurements. Additionally, we used canopy conductance data from sap flux measurements, assuming that canopy conductance $G_{c}=G_{s}$. $G_{c}$ differs from $G_{s}$ in that $G_{c}$ does not include the effect of soil surface evaporation (including understory evaporation) (Kelliher et al., 1995; Raupach, 1995). However, 
$G_{c}$ is approximately equal to $G_{s}$ when the projected LAI is $\geq c a 3$ because of the insignificant contribution of soil surface evaporation to total evaporation (Kelliher et al., 1995). Thus, our assumption $\left(G_{c}=G_{s}\right)$ is reasonable. Although $G_{c}$ can also be obtained by scaling up from leaf gas exchange measurements (Whitehead et al., 1984; Milne et al., 1985; Loustau et al., 1996), we did not use such data. They are not very representative of forest gas exchange characteristics, as there is large variation in the gas exchange rate between leaves in a forest (Leverenz et al., 1982).

As detailed above, we used $G_{s}$ data based on different measurement methods. The effects of these differences in measurement methods on the analysis results have been discussed by Komatsu (2003b).

\section{RESULTS AND DISCUSSION}

Figure 2(a) shows the relation between canopy height $h$ and $\hat{G}_{\text {smax }}$ for coniferous forests with projected LAI $\geq 3 \cdot 0$, which is the same as Figure 2(b) of Komatsu (2003b). Figure 2(b) of our paper shows the relation between $h$ and $G_{\text {smax }}$ for coniferous forests with projected LAI $\geq 3 \cdot 0$. $\hat{G}_{\text {smax }}$ and $G_{\text {smax }}$ data used in Figure 2(a) and (b) are shown in Table I. Note that we have included two samples (Arain et al., 2003; Restrepo and Arain, 2005) that had not been included in the Komatsu (2003b) analysis. As a result, the $R^{2}$ value in Figure 2 (a) $\left(R^{2}=0.61\right)$ differed slightly from that in Figure 2(b) of Komatsu (2003b) $\left(R^{2}=0.69\right)$.

Both $\hat{G}_{\text {smax }}$ and $G_{\text {smax }}$ decreased with increasing $h$. However, the relation between $h$ and $G_{\text {smax }}$ was less well defined than the relationship between $h$ and $\hat{G}_{\text {smax }}$. The $R^{2}$ for Figure 2(b) $\left(R^{2}=0.49\right)$ was lower than that for Figure 2(a) $\left(R^{2}=0 \cdot 61\right)$.

The less well defined relationship in Figure 2(b) was caused by the two data samples indicated by arrows. These two samples were from Tanaka et al. (1996) and Restrepo and Arain (2005), respectively. We believe that the $G_{\text {smax }}$ values for Tanaka et al. (1996) and Restrepo and Arain (2005) are biased, for the following reasons. First, the $R^{2}$ values for Figure 2(a) and (b) are similar to each other if these two data samples are excluded. When they are excluded, the $R^{2}$ values for Figure 2(a) and (b) are 0.68 and 0.67 , respectively. Second, $G_{\text {smax }}$ values for Tanaka et al. (1996) and Restrepo and Arain (2005) are much higher than those expected from their $\hat{G}_{\text {smax }}$ values. Figure 3 shows the relationship between $\hat{G}_{\text {smax }}$ and $G_{\text {smax }}$. Data from Tanaka et al. (1996) and Restrepo and Arain (2005) are indicated by arrows. There is a clear linear relationship between $\hat{G}_{\text {smax }}$ and $G_{\text {smax }}\left(R^{2}=0.70\right)$, which explains qualitatively the same results between Figure 2(a) and (b). However, the data of Tanaka et al. (1996) and Restrepo and Arain (2005) deviate noticeably from the regression line (Figure 3). The two data samples show much higher $G_{\text {smax }}$ values than those expected from the regression line between $\hat{G}_{\text {smax }}$ and $G_{\text {smax }}$.

The scatter in the $G_{\text {smax }}$ value for Tanaka et al. (1996) and Restrepo and Arain (2005) may be explained by
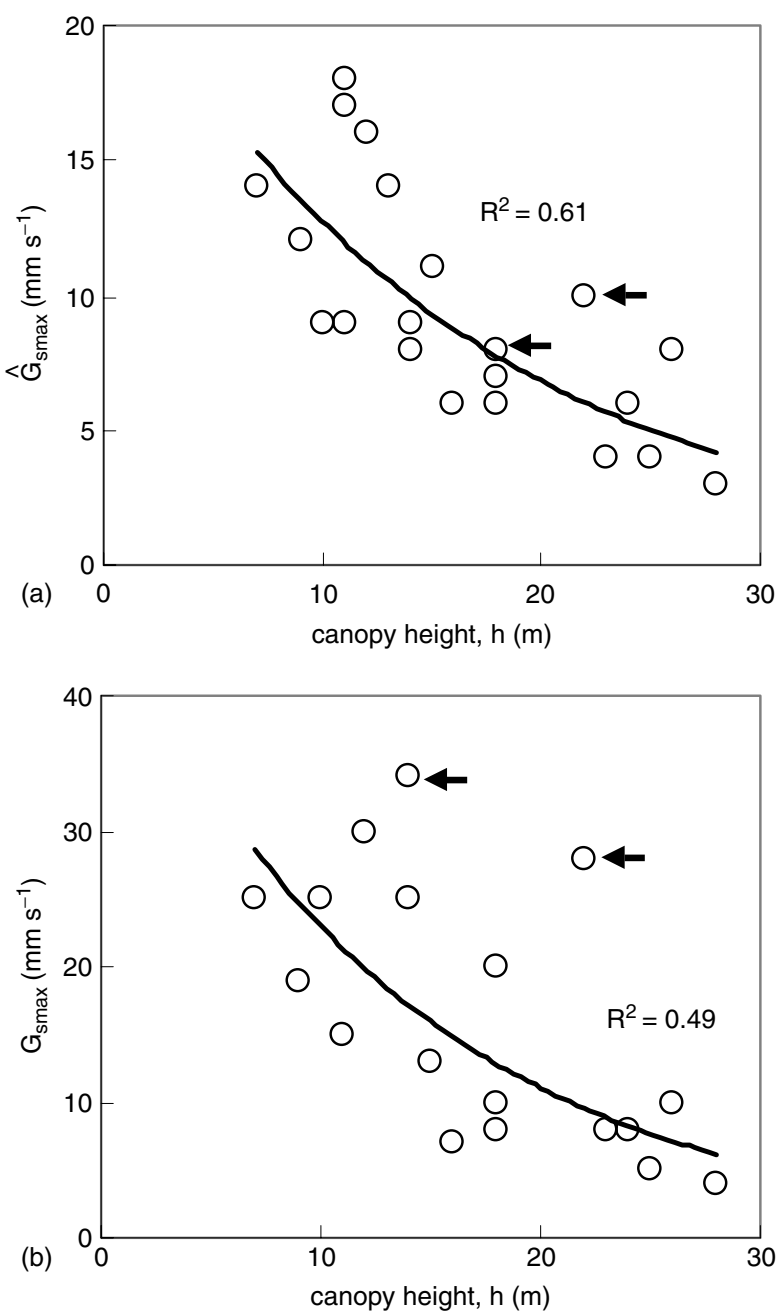

Figure 2. (a) The relationship between canopy height $h$ and $\hat{G}_{\text {smax }}$ for coniferous forests with projected LAI $\geq 3 \cdot 0$, where $\hat{G}_{\text {smax }}$ is the maximum surface conductance satisfying VPD $\geq 1.0 \mathrm{kPa}$ during the measurement period. The function determined by least-square regression is written as $\hat{G}_{\text {smax }}=23.7 \exp (-0.0624 h)$. Data from Tanaka et al. (1996) and Restrepo and Arain (2005) are indicated by arrows. (b) The relationship between canopy height $h$ and $G_{\text {smax }}$ for coniferous forests with projected LAI $\geq 3 \cdot 0$, where $G_{\text {smax }}$ is the maximum surface conductance during the measurement period. The function determined by least-square regression is written as $G_{\text {smax }}=47.7 \exp (-0.0731 \mathrm{~h})$. Data from Tanaka et al. (1996) and Restrepo and Arain (2005) are indicated by arrows

wet-canopy evaporation and/or VPD measurement error factors. As described in the Theory section, there are three possible factors that explain scatter in $G_{\text {smax }}$ : short measurement period, wet-canopy evaporation, and VPD measurement error factors. The short measurement period factor cannot explain the scatter. It can only cause underestimation of $G_{\text {smax }}$ values. However, Figure 3 suggests that the $G_{\text {smax }}$ is overestimated rather than underestimated. Apart from the short measurement period factor, both wet-canopy evaporation and VPD measurement error factors can cause overestimation of $G_{\text {smax }}$ values.

\section{CONCLUSIONS}

We examined whether $\hat{G}_{\text {smax }}$ and $G_{\text {smax }}$ both lead to the same conclusions when used for comparing $G_{s}$ 
Table I. $\hat{G}_{\text {smax }}$ and $G_{\text {smax }}$ values for coniferous forests with projected LAI of $\geq 3 \cdot 0$ summarized from earlier papers

\begin{tabular}{|c|c|c|c|c|c|c|c|}
\hline Species & $\begin{array}{l}\text { Latitude, } \\
\text { Longitude }\end{array}$ & $\begin{array}{c}\text { Canopy } \\
\text { height } \\
\text { (m) }\end{array}$ & $\begin{array}{c}\text { Projected } \\
\text { leaf area } \\
\text { index }\end{array}$ & $\begin{array}{l}\text { Measure- } \\
\text { ment } \\
\text { methods }^{\mathrm{a}}\end{array}$ & $\begin{array}{c}\hat{G}_{\text {smax }} \\
\left(\mathrm{mm} \mathrm{s}^{-1}\right)\end{array}$ & $\begin{array}{c}G_{\text {smax }} \\
\left(\mathrm{mm} \mathrm{s}^{-1}\right)\end{array}$ & Reference \\
\hline Abies bornmulleiana & $?$ & 11 & $8 \cdot 9$ & SF & $18^{\mathrm{b}}$ & - & Granier et al. (2000) \\
\hline Chamaecyparis obtusa & $34^{\circ} 58^{\prime} \mathrm{N}, 136^{\circ} 00^{\prime} \mathrm{E}$ & 14 & $3 \cdot 0$ & $\mathrm{EC}$ & 8 & 34 & Tanaka et al. (1996) \\
\hline Larix gmelinii & $62^{\circ} 15^{\prime} \mathrm{N}, 129^{\circ} 37^{\prime} \mathrm{E}$ & 18 & $3 \cdot 7$ & $\mathrm{EC}$ & 8 & 20 & Ohta et al. (2001) \\
\hline Picea abies & $56^{\circ} 34^{\prime} \mathrm{N}, 13^{\circ} 13^{\prime} \mathrm{E}$ & 14 & 9 & $\mathrm{SF}$ & 9 & 25 & Cienciala et al. (1994) \\
\hline Picea abies & $50^{\circ} 09^{\prime} \mathrm{N}, 11^{\circ} 52^{\prime} \mathrm{E}$ & 15 & $6 \cdot 5$ & $\mathrm{SF}$ & 11 & 13 & Alsheimer et al. (1998) \\
\hline Picea abies & $50^{\circ} 09^{\prime} \mathrm{N}, 11^{\circ} 52^{\prime} \mathrm{E}$ & 16 & $5 \cdot 3$ & $\mathrm{SF}$ & 6 & 7 & Alsheimer et al. (1998) \\
\hline Picea abies & $50^{\circ} 09^{\prime} \mathrm{N}, 11^{\circ} 52^{\prime} \mathrm{E}$ & 18 & $7 \cdot 1$ & SF & 7 & 8 & Alsheimer et al. (1998) \\
\hline Picea abies & $50^{\circ} 09^{\prime} \mathrm{N}, 11^{\circ} 52^{\prime} \mathrm{E}$ & 24 & $7 \cdot 9$ & $\mathrm{SF}$ & 6 & 8 & Alsheimer et al. (1998) \\
\hline Picea abies & $50^{\circ} 09^{\prime} \mathrm{N}, 11^{\circ} 52^{\prime} \mathrm{E}$ & 25 & $6 \cdot 5$ & SF & 4 & 5 & Alsheimer et al. (1998) \\
\hline Picea abies & $50^{\circ} 09^{\prime} \mathrm{N}, 11^{\circ} 52^{\prime} \mathrm{E}$ & 26 & $7 \cdot 6$ & SF & 8 & 10 & Alsheimer et al. (1998) \\
\hline Picea abies & ? & 11 & $9 \cdot 5$ & $\mathrm{SF}$ & $17^{\mathrm{b}}$ & - & Granier et al. (2000) \\
\hline Picea abies & ? & 13 & $6 \cdot 1$ & SF & $14^{\mathrm{b}}$ & - & Granier et al. (2000) \\
\hline Picea sitchensis & $55^{\circ} 20^{\prime} \mathrm{N}, 3^{\circ} 53^{\prime} \mathrm{W}$ & 7 & $5^{\mathrm{d}}$ & ECEB & 14 & 25 & Milne (1979) \\
\hline Pinus banksiana & $53^{\circ} 59^{\prime} \mathrm{N}, 105^{\circ} 07^{\prime} \mathrm{W}$ & 11 & 4.5 & EC & 9 & 15 & Arain et al. (2003) \\
\hline Pinus pinaster & $44^{\circ} 42^{\prime} \mathrm{N}, 0^{\circ} 46^{\prime} \mathrm{W}$ & 12 & 6 & SF & 16 & 30 & $\begin{array}{l}\text { Granier and Loustau } \\
\text { (1994) }\end{array}$ \\
\hline Pinus radiata & $42^{\circ} 52^{\prime} \mathrm{S}, 172^{\circ} 45^{\prime} \mathrm{E}$ & 9 & $6.5 \sim 7.5$ & $\mathrm{EC}$ & 12 & 19 & Arneth et al. (1998) \\
\hline Pinus strobus & $42^{\circ} 43^{\prime} \mathrm{N}, 80^{\circ} 23^{\prime} \mathrm{W}$ & 22 & $3 \cdot 2 \sim 4 \cdot 0$ & $\mathrm{EC}$ & 10 & 28 & $\begin{array}{l}\text { Restrepo and Arain } \\
\text { (2005) }\end{array}$ \\
\hline Pinus sylvestris/Picea abies & $60^{\circ} 05^{\prime} \mathrm{N}, 17^{\circ} 29^{\prime} \mathrm{E}$ & 28 & $3 \sim 4$ & SF & 3 & 4 & Cienciala et al. (1997) \\
\hline Pinus sylvestris/Picea abies & $60^{\circ} 05^{\prime} \mathrm{N}, 17^{\circ} 29^{\prime} \mathrm{E}$ & 23 & $4 \sim 5$ & $\mathrm{SF}$ & 4 & 8 & Cienciala et al. (1997) \\
\hline Pseudotsuga menziesii & ? & 10 & $7.5 \sim 8.0$ & BREB & 9 & 25 & Tan and Black (1976) \\
\hline Pseudotsuga menziesii & $52^{\circ} 15^{\prime} \mathrm{N}, 5^{\circ} 41^{\prime} \mathrm{W}$ & 18 & 11 & $\mathrm{EC}$ & 6 & 10 & $\begin{array}{l}\text { Bosveld and Bouten } \\
\text { (2001) }\end{array}$ \\
\hline
\end{tabular}

${ }^{a}$ BREB: Bowen ration energy balance method; EC: eddy correlation method; ECEB: eddy correlation energy balance method; SF: sap flux method. ${ }^{b}$ Derived from the regression model of Granier et al. (2000), which expresses $G_{s}$ as a function of meteorological factors. We assumed that $\hat{G}_{\text {smax }}$ equals the maximum $G_{s}$ at VPD $=1.0 \mathrm{kPa}$. Even when these data samples are excluded, our conclusions are not altered.

${ }^{\mathrm{c}} G_{\text {smax }}$ could not be derived from the regression model of Granier et al. (2000), because $G_{s}$ was assumed to approach infinity as VPD approaches $0 \mathrm{kPa}$.

${ }^{\mathrm{d}}$ Estimated by dividing the total surface area index by 2.4 , which is an intermediate value for conifers (Landsberg and Gower, 1997).

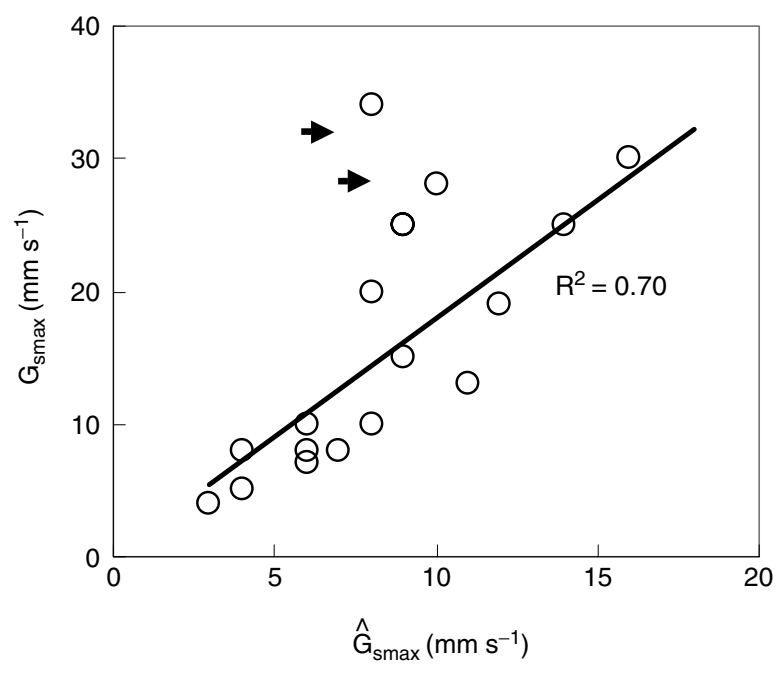

Figure 3 . The relationship between $\hat{G}_{\text {smax }}$ and $G_{\text {smax }}$, where $\hat{G}_{\text {smax }}$ is the maximum surface conductance satisfying VPD $\geq 1.0 \mathrm{kPa}$ during the measurement period, and $G_{s \max }$ is the maximum surface conductance during the measurement period. Data from Tanaka et al. (1996) and Restrepo and Arain (2005) are indicated by arrows. The function determined by least-square regression is written as $G_{\text {smax }}=1 \cdot 79 \cdot \hat{G}_{\text {smax }}$. For this regression, data from Tanaka et al. (1996) and Restrepo and Arain (2005) were excluded

values between different observation sites. For this purpose, we examined the relation between canopy height $h$ and $\hat{G}_{\text {smax }}$, and between $h$ and $G_{\text {smax }}$ for coniferous forests with projected LAI of $\geq 3 \cdot 0$. Both $\hat{G}_{\text {smax }}$ and $G_{\text {smax }}$ decreased with increasing $h$. However, the relation between $h$ and $G_{\text {smax }}$ was less well defined than the relationship between $h$ and $\hat{G}_{\text {smax }}$, because of biased $G_{\text {smax }}$ data samples. Thus, we have shown a clear justification for using $\hat{G}_{\text {smax }}$ instead of $G_{\text {smax }}$. Consequently, we conclude that $\hat{G}_{\text {smax }}$ is a more appropriate index than $G_{\text {smax }}$ to represent $G_{s}$ for different vegetated sites.

\section{ACKNOWLEDGEMENTS}

We would like to thank Dr Tomo'omi Kumagai (Kyushu University, Japan) and Dr Haruhiko Taneda (The University of Tokyo, Japan) for their comments on micrometeorological and porometry measurements, respectively.

This research was supported by Research Fellowships of the Japan Society for the Promotion of Science for Young Scientists (\#16.6152) and by the Japanese Ministry of Education, Culture, Sports, Science and Technology, Grant-in-Aid for Scientific Research (\#17380096 and \#18810023).

\section{REFERENCES}

Alsheimer M, Kostner B, Falge E, Tenhunen JD. 1998. Temporal and spatial variation in transpiration of Norway spruce stands within 
a forested catchment of the Fichtelgebirge, Germany. Annales Des Sciences Forestieres 55: 103-123.

Arain MA, Black TA, Barr AG, Griffis TJ, Morgenstern K, Nesic Z. 2003. Year-round observations of the energy and water vapour fluxes above a boreal black spruce forest. Hydrological Processes 17: 3581-3600.

Arneth A, Kelliher FM, McSeveny TM, Byers JN. 1998. Fluxes of carbon and water in a Pinus radiata forest subject to soil water deficit. Australian Journal of Plant Physiology 25: 557-570.

Baldocchi DD, Meyers TP. 1998. On using eco-physiological, micrometeorological and biogeochemical theory to evaluate carbon dioxide, water vapor and trace gases fluxes over vegetation: a perspective. Agricultural and Forest Meteorology 90: 1-25.

Blanken PD, Black TA. 2004. The canopy conductance of a boreal aspen forest, Prince Albert National Park, Canada. Hydrological Processes 18: $1561-1578$.

Bosveld FC, Bouten W. 2001. Evaluation of transpiration models with observations over Douglas-fir forest. Agricultural and Forest Meteorology 108: 247-264.

Campbell GS, Norman JM. 1998. An Introduction to Environmental Biophysics. Springer-Verlag: New York; 286.

Cienciala E, Lindroth A, Cermak J, Hallgren J, Kucera J. 1994. The effects of water availability on transpiration, water potential and growth of Picea abies during a growing season. Journal of Hydrology 155 $57-71$

Cienciala E, Kucera K, Lindroth A, Cermak J, Grelle A, Halldin S. 1997. Canopy transpiration from a boreal forest in Sweden during a dry year. Agricultural and Forest Meteorology 86: 157-167.

Dolman AJ, Gash JHC, Roberts J, Shuttleworth WJ. 1991. Stomatal and surface conductance of tropical rainforest. Agricultural and Fores Meteorology 54: 303-318.

Dolman AJ, Moors EJ, Elbers JA, Snijders W. 1998. Evaporation and surface conductance of three temperate forests in the Netherlands. Annales Des Sciences Forestieres 55: 255-270.

Ewers BE, Oren R. 2000. Analyses of assumptions and errors in the calculation of stomatal conductance from sap flux measurements. Tree Physiology 20: 579-589.

Ewers BE, Gower ST, Bond-Lamberty B, Wang CK. 2005. Effects of stand age and tree species on canopy transpiration and average stomatal conductance of boreal forests. Plant Cell and Environment 28: $660-678$.

Gash JHC, Shuttleworth WJ, Lloyd CR, Andre JC, Goutorbe JP, Gelpe J. 1989. Micrometeorological measurements in Les Landes forest during HAPEX-MOBILHY. Agricultural and Forest Meteorology 46 $131-147$.

Granier A, Loustau D. 1994. Measuring and modelling the transpiration of a maritime pine canopy from sap-flow data. Agricultural and Fores Meteorology 71: 61-81.

Granier A, Huc R, Barigah ST. 1996a. Transpiration of natural rain forest and its dependence on climatic factors. Agricultural and Forest Meteorology 78: 19-29.

Granier A, Biron P, Kostner B, Gay LW, Najjar G. 1996b. Comparisons of xylem sap flow and water vapour flux at the stand level and derivation of canopy conductance for Scots pine. Theoretical and Applied Climatology 53: 115-122.

Granier A, Loustau D, Breda N. 2000. A generic model of forest canopy conductance dependent on climate, soil water availability and leaf area index. Annals of Forest Science 57: 755-765.

Herbst M. 1995. Stomatal behaviour in a beech canopy: an analysis of Bowen ratio measurements compared with porometer data. Plant Cell and Environment 18: 1010-1018

Humphreys ER, Black TA, Ethier GJ, Drewitt GB, Spittlehouse DL, Jork EM, Nesic Z, Livingston NJ. 2003. Annual and seasonal variability of sensible and latent heat fluxes above a coastal Douglas-fir forest, British Columbia, Canada. Agricultural and Forest Meteorology 115: $109-125$.

Jones HG. 1992. Plants and Microclimate. Cambridge University Press Cambridge; 428.

Kelliher FM, Leuning R, Schulze ED. 1993. Evaporation and canopy characteristics of coniferous forests and grasslands. Oecologia $\mathbf{9 5}$ $153-163$

Kelliher FM, Leuning R, Raupach MR, Schulze ED. 1995. Maximum conductances for evaporation from global vegetation types. Agricultural and Forest Meteorology 73: 1-16.

Kelliher FM, Hollinger DY, Schulze ED, Vyodskaya NN, Byers JN Hunt JE, McSeveny TM, Milukova I, Sogatchev A, Varlargin A, Ziegler W, Arneth A, Bauer G. 1997. Evaporation from an eastern Siberian larch forest. Agricultural and Forest Meteorology $\mathbf{8 5}$ $135-147$.
Kelliher FM, Lloyd J, Arneth A, Byers JN, McSeveny TM, Milukova I, Grigoriev S, Panfyorov M, Sogatchev A, Varlargin A, Ziegler W, Bauer G, Schulze ED. 1998. Evaporation from a central Siberian pine forest. Journal of Hydrology 205: 279-296.

Komatsu H. 2003a. Values of the decoupling factor observed on forest canopies. Journal of Japan Society of Hydrology and Water Resources 16: 423-438, (in Japanese with English summary).

Komatsu H. 2003b. Relationship between canopy height and the reference value of surface conductance for closed coniferous stands. Hydrological Processes 17: 2503-2512.

Komatsu H. 2004. A general method of parameterizing the big-leaf model to predict the dry-canopy evaporation rate of individual coniferous forest stands. Hydrological Processes 18: 3019-3036.

Komatsu H. 2005. Forest categorization according to dry-canopy evaporation rates in a growing season: comparison of the PriestleyTaylor coefficient values from various observation sites. Hydrological Processes 19: 3873-3896.

Komatsu H, Hotta N. 2005. What was clarified with the increase of forest evapotranspiration studies based on flux measurements? Journal of Japan Society of Hydrology and Water Resources 18: 613-626, (in Japanese with English summary).

Komatsu H, Kumagai T, Hotta N. 2005. Is surface conductance theoretically independent of reference height? Hydrological Processes 19: $339-347$.

Komatsu H, Kumagai T, Hotta N. 2007. Effects of vertical air temperature distribution within forest canopies on photosynthesis and transpiration. Bulltin of Kyushu University Forest (in press).

Komatsu H, Kang Y, Kume T, Yoshifuji N, Hotta N. 2006. Transpiration from a Cryptomeria japonica plantation, part 2: responses of canopy conductance to meteorological factors. Hydrological Processes 20: $1321-1334$

Kostner B. 2001. Evaporation and transpiration from forests in Central Europe - relavance of patch-level studies for spatial scaling. Meteorology and Atmospheric Physics 76: 69-82.

Kumagai T, Saitoh TM, Sato Y, Morooka T, Manfroi OJ, Kuraji K, Suzuki M. 2004. Transpiration, canopy conductance and the decoupling coefficient of a lowland mixed dipterocarp forest in Sarawak, Borneo: dry spell effects. Journal of Hydrology 287: $238-252$.

Lai CT, Katul GG, Oren R, Ellsworth D, Schafer K. 2000. Modeling $\mathrm{CO}_{2}$ and water vapor turbulent flux distributions within a forest canopy. Journal of Geophysical Research 102: 26333-26351.

Landsberg JJ, Gower ST. 1997. Applications of Physiological Ecology to Forest Management. Academic Press: San Diego, CA; 354.

Law BE, Goldstein AH, Anthoni PM, Unsworth MH, Panek JA, Bauer MR, Fracheboud JM, Hultman N. 2001. Carbon dioxide and water vapor exchange by young and old ponderosa pine ecosystems during a dry summer. Tree Physiology 21: 299-308.

Leuning R. 1990. Modelling stomatal behaviour and photosynthesis of Eucalyptus grandis. Australian Journal of Plant Physiology 17: $159-175$.

Leuning R. 1995. A critical appraisal of a combined stomatalphotosynthesis model for $\mathrm{C}_{3}$ plants. Plant Cell and Environment 18: $339-355$.

Leverenz JW, Deans JD, Ford ED, Jarvis PG, Milne R, Whitehead D. 1982. Systematic spatial variation of stomatal conductance in a Sitka spruce plantation. Journal of Applied Ecology 19: 835-851.

Lindroth A. 1985. Canopy conductance of coniferous forests related to climate. Water Resources Research 21: 297-304.

Loustau D, Berbigier P, Roumagnac P, Arruda-Pacheco C, David JS, Ferreira MI, Pereira JS, Tavares R. 1996. Transpiration of a 64-yearold maritime pine stand in Portugal. 1. Seasonal course of water flux through maritime pine. Oecologia 107: 33-42.

Milne R. 1979. Water loss and canopy resistance of a young Sitka spruce plantation. Boundary-Layer Meteorology 16: 67-81.

Milne R, Deans JD, Ford ED, Jarvis PD, Leverenz J, Whitehead D. 1985. A comparison of two methods of estimating transpiration rates from a Sitka spruce plantation. Boundary-Layer Meteorology 32: $155-175$.

Ogink-Hendriks MJ. 1995. Modelling surface conductance and transpiration of an oak forest in The Netherlands. Agricultural and Forest Meteorology 74: 99-118.

Ohta T, Hiyama T, Tanaka H, Kuwada T, Maximov TC, Ohata T, Fukushima Y. 2001. Seasonal variation in the energy and water exchanges above and below a larch forest in eastern Siberia. Hydrological Processes 15: 1459-1476.

Oren R, Sperry JS, Pataki DE, Ewers BE, Phillips N, Schafer KVR. 1999. Survey and synthesis of intra- and interspecific variation 
in stomatal sensitivity to vapour pressure deficit. Plant Cell and Environment 22: 1515-1526.

Raupach MR. 1995. Vegetation-atmosphere interaction and surface conductance at leaf, canopy and regional scales. Agricultural and Forest Meteorology 73: 151-179.

Restrepo NC, Arain MA. 2005. Energy and water exchanges from a temperate pine plantation forest. Hydrological Processes 19: 27-49.

Schulze ED, Leuning R, Kelliher FM. 1995. Environmental regulation of surface conductance for evaporation from vegetation. Vegetatio 121: $79-87$.

Schulze ED, Kelliher FM, Korner C, Lloyd J, Leuning R. 1994. Relationships among maximum stomatal conductance, ecosystem surface conductance, carbon assimilation rate, and plant nitrogen nutrition: a global ecology scaling exercise. Annual Review of Ecology and Systematics 25: 629-660.
Shuttleworth WJ. 1989. Micrometeorology of temperate and tropical forest. Philosophical Transactions of the Royal Society of London Series B-Biological Sciences 324: 299-334.

Stewart JB. 1988. Modeling surface conductance of pine forest. Agricultural and Forest Meteorology 43: 19-35.

Tan CS, Black TA. 1976. Factors affecting the canopy resistance of a douglas-fir forest. Boundary-Layer Meteorology 10: 475-488.

Tanaka K, Tanaka H, Nakamura A, Ohte N, Kobashi S. 1996. Conductance at a community level and characteristics of $\mathrm{CO}_{2}$ exchange in hinoki (Chamaecyparis obtusa) stand. Journal of the Japan Forestry Society 78: 266-272, (in Japanese with English summary).

Whitehead D, Jarvis PG, Waring RH. 1984. Stomatal conductance, transpiration, and resistance to water uptake in a Pinus sylvestris spacing experiment. Canadian Journal of Forest Research 14: $692-700$. 